\title{
Identification of dissociation factors in pancreatic Cancer using a mass spectrometry-based proteomic approach
}

\author{
Peng Liu', Lingming Kong ${ }^{1}$, Keke Liang ${ }^{1}$, Yunhao Wu', Haoyi Jin, Bing Song ${ }^{1,2}$ and Xiaodong Tan ${ }^{1 *}$
}

\begin{abstract}
Backgroud: Pancreatic cancer is a highly malignant tumor of the digestive system. This secretome of pancreatic cancer is key to its progression and metastasis. But different methods of protein extraction affect the final results. In other words, the real secretion of proteins in cancer cells has been changed. Based on mass spectrometry, we analyze the secretome from the serum-containing and serum-free medium, using different protein pretreatment methods. This study aims to identify dissociation factors in pancreatic cancer.

Methods: In this study, pancreatic cancer cells were cultured in serum-containing or serum-free medium, and the corresponding supernatants were extracted as samples. Subsequently, the above samples were separated by size exclusion chromatography (SEC), and peptide segments were identified by LC-MS/MS. The final results were identified via the hamster secreted protein database and a public database.
\end{abstract}

Results: Although the number of identified proteins in the serum-free medium group was high, the real secretion of proteins in pancreatic cancer cells was changed. There were six significant secreted proteins in the serumcontaining medium group. Survival analysis via the TCGA database suggested that patients with higher expression levels of YWHAG showed a worse overall survival rate than those with lower YWHAG expression.

Conclusions: Our study demonstrated the results in the serum-containing medium group were more similar to the real secretome of pancreatic cancer cells. YWHAG could be used as a prognostic indicator for pancreatic cancer.

Keywords: Pancreatic cancer, Secreted proteome, SEC, Mass spectrum

\section{Background}

Pancreatic cancer is the fourth leading cause of cancer death worldwide and is characterized by rapid progression, high invasiveness, and resistance to chemotherapeutic drugs. The latest survey of malignant tumors in China showed that the mortality rate of pancreatic cancer ranks sixth [1-3]. More than $80 \%$ of patients with pancreatic cancer are diagnosed with local invasion or even distant metastasis. Theoretically, the possibility of surgical resection is lost, and only palliative treatment is tolerated [4]. In addition, patients undergoing radical surgery have a median survival time of only 18 months [5]. Early diagnosis and appropriate treatment can

\footnotetext{
*Correspondence: tanxdcmu@163.com

${ }^{1}$ Department of General Surgery, Shengjing Hospital of China Medical University, Shenyang 110004, China

Full list of author information is available at the end of the article
}

significantly improve the prognosis of pancreatic cancer. With the development of experimental techniques, the number of molecular detection methods for cancer is increasing. These methods play an important role in the early diagnosis of pancreatic cancer [6]. In a previous study, we used two cell lines derived from the hamster model of pancreatic cancer that have distinct invasion and metastasis abilities: a nondissociated, low-metastasis pancreatic cancer cell line (PC-1) and a dissociated, high-metastasis pancreatic cancer cell line (PC-1.0). Conditioned medium was prepared from the purified supernatant of PC-1.0 cells and used to culture PC-1 cells. The growth state of PC-1 cells was changed and exhibited the growth state of PC-1.0 cells. Therefore, we concluded that the supernatant of PC-1.0 cells contains key factors that can promote changes in cell biological behavior, which we call dissociation factors (DF) [7, 8]. 


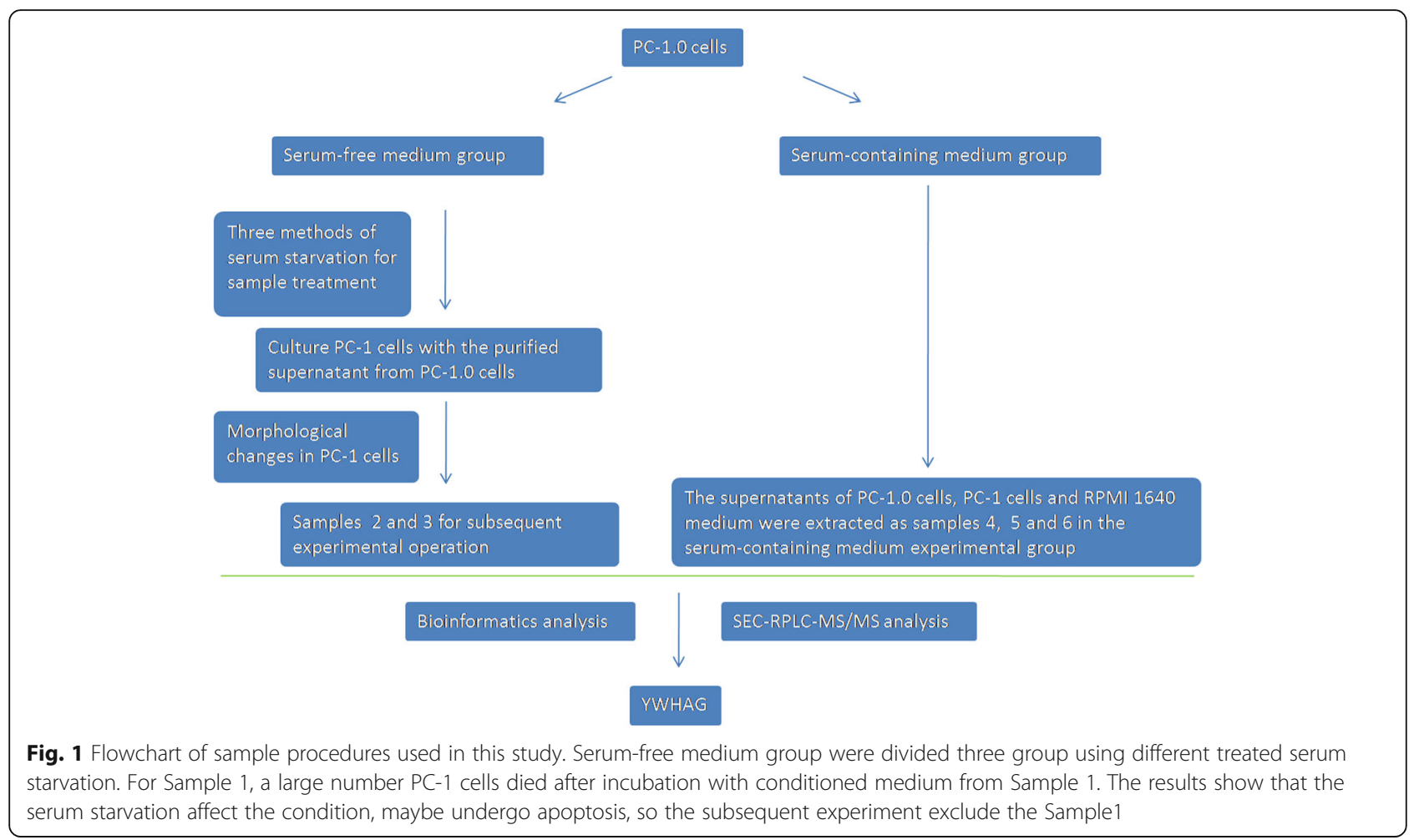

The purpose of this experiment was to identify dissociation factors by using different sample pretreatment methods combined with size exclusion chromatography.

\section{Methods}

\section{Cell lines and cell culture}

PC-1 cells grew as islet-like colonies of cells, whereas PC1.0 cells grew as single cells. The source and incubation conditions of the cells were described previously [9].

\section{Materials}

Acetonitrile (ACN) and methanol were purchased from Merck Company (Germany); glacial acetic acid, from Damao Chemical Reagent Factory in Tianjin; and bovine serum albumin (BSA), from Sigma-Aldrich Company (USA). Trypsin (bovine pancreas), formic acid, trifluoroacetic acid, urea, protease inhibitor cocktail, dithiothreitol, trichloroacetic acid, acetone, and iodoacetamide were purchased from Sigma-Aldrich (St. Louis, MO, USA). All experimental water was purified by a Milli-Q system (Millipore Corporation, USA). A Thermo SEC120 HPLC column $(5 \mu \mathrm{m}, 120 \AA)$ was used. An Ultimate 3000 chromatograph and Thermo LTQ-Orbitrap mass spectrometer were used for detection.

\section{Effects of serum-free conditioned medium from PC-1.0 cells on the activity of PC-1 cells}

Preparation of serum-free conditioned medium: Three methods were used to prepare conditioned medium from PC-1.0 cells, which was used to treat cultured PC-1 cells for $24 \mathrm{~h}$; then, morphological changes in PC-1 cells were observed. The following methods were used: Method 1: PC-1.0 cells were washed 5 times with PBS; Method 2: PC-1.0 cells were washed 3 times with PBS
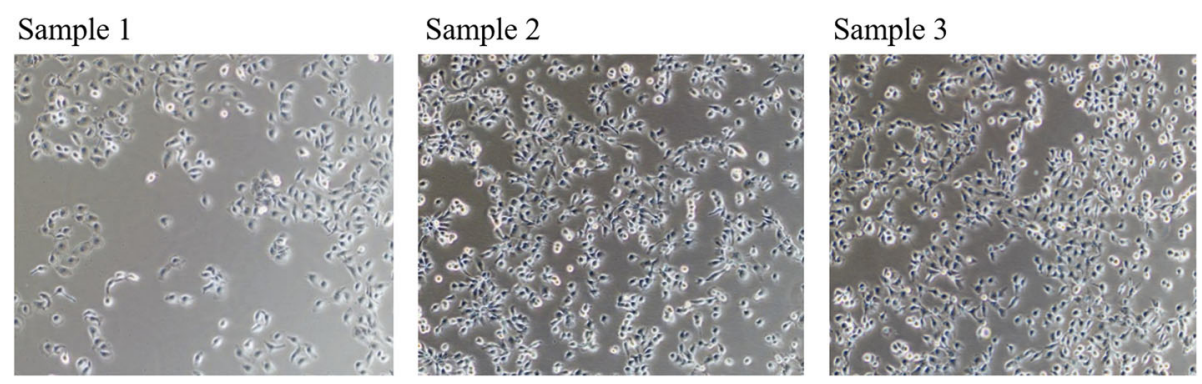

Fig. 2 Changes in PC-1.0 cells after serum starvation observed by microscopy 

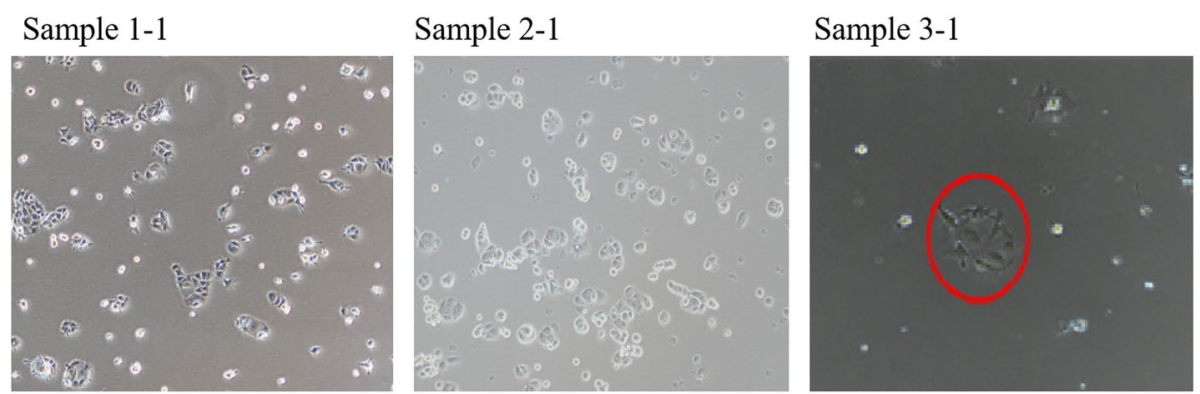

Fig. 3 PC-1 cell morphology $12 \mathrm{~h}$ after the addition of PC-1.0 supernatant. A large number of PC-1 cells died after incubation with conditioned medium from Sample 1; the number of PC-1 cells after incubation with Sample 2 medium exhibited a relative decrease, and there was no obvious separation trend; and the growth status of PC-1 cells after treatment with Sample 3 medium changed.

and incubated 2 times with phenol-free medium (Gibco, Grand Island, NY) for 20 min each; And Method 3: PC1.0 cells were incubated in $2 \% \mathrm{PBS}+$ phenol-free medium for $20 \mathrm{~min}$ and in phenol-free medium 4 times for 20 min each. The supernatants of the above samples were extracted and used to prepare the culture medium.

\section{Extraction of total protein from samples}

PC-1.0 cell and PC-1 cell supernatants and RPMI 1640 medium (negative control group) were extracted as samples 4, 5 and 6 in the serum-containing medium experimental group. Each sample was spun at $12000 \mathrm{r} / \mathrm{min}$ through a $0.22 \mu \mathrm{m}$ fiber filter and concentrated using a $3 \mathrm{kDa}$ concentrating tube by centrifuging at $3500 \times \mathrm{g}$ for $120 \mathrm{~min}$. The protein concentration was measured using the BCA method.

\section{SEC-RPLC-MS/MS analysis}

Low-abundance proteins were enriched on a size exclusion chromatography (SEC) column. The $200 \mu \mathrm{l}$ sample was washed for 10 min with buffer $\mathrm{A}$ at a flow rate of $0.5 \mathrm{ml} / \mathrm{min}$. After collecting the effluent components, the remaining fractions were eluted with buffer $B$ at a flow rate of $1 \mathrm{ml} / \mathrm{min}$ for $7 \mathrm{~min}$, and the collected fractions were stored at $-20^{\circ} \mathrm{C}$ for use. The effluent components collected were centralized in a rotary concentrator with a $5 \mathrm{kDa}$ molecular weight cutoff membrane and centrifuged at $10^{\circ} \mathrm{C}$ for $5000 \mathrm{r} / \mathrm{min}$. Samples were collected for subsequent application.

An Ultimate 3000 chromatograph and a Thermo LTQOrbitrap mass spectrometer were used for detection.

Table 1 Protein spectrum data results

\begin{tabular}{lllll}
\hline Species Sample & Protein & Hamster & Hamster - secreted protein & Bovine \\
\hline No. 2 & 1378 & 987 & 99 & 391 \\
No. 3 & 1496 & 1092 & 111 & 404 \\
No. 4 & 230 & 62 & 25 & 168 \\
No. 5 & 284 & 105 & 28 & 179 \\
No. 6 & 236 & 65 & 21 & 171 \\
\hline
\end{tabular}

Peptides were loaded on an in-house-packed C18 capillary trap column $(150 \mu \mathrm{m}$ i.d. $\times 4 \mathrm{~cm})$ and separated using a C18 separation column $(75 \mu \mathrm{m}$ i.d. $\times 15 \mathrm{~cm})$. Phase A was $98 \% \mathrm{H}_{2} \mathrm{O}+2 \% \mathrm{ACN}$ with $0.1 \% \mathrm{FA}$, and phase $\mathrm{B}$ was $2 \%$ $\mathrm{H}_{2} \mathrm{O}+98 \%$ ACN with $0.1 \%$ FA. The gradient was as follows: $0-6 \%$ phase B for $10 \mathrm{~min}, 6-35 \%$ phase B for 100 min, $35-80 \%$ phase B for $10 \mathrm{~min}$, and $80 \%$ phase B for 10 $\mathrm{min}$. The temperature of the ion transfer capillary was set at $275^{\circ} \mathrm{Cwith}$ a spray voltage of $2.7 \mathrm{kV}$. The scan range was set from $\mathrm{m} / \mathrm{z}=300-1800$. There was a $20 \mathrm{~s}$ exclusion window. Raw spectrum data were searched using Mascot (2.3.2). For classifying the obtained protein results, the database species used in the experiment were both hamster and bovine. Mass tolerances were set at $7 \mathrm{ppm}$ for parent ions and $20 \mathrm{ppm}$ for fragments. The fixed modification was cysteine alkylation, and the variable

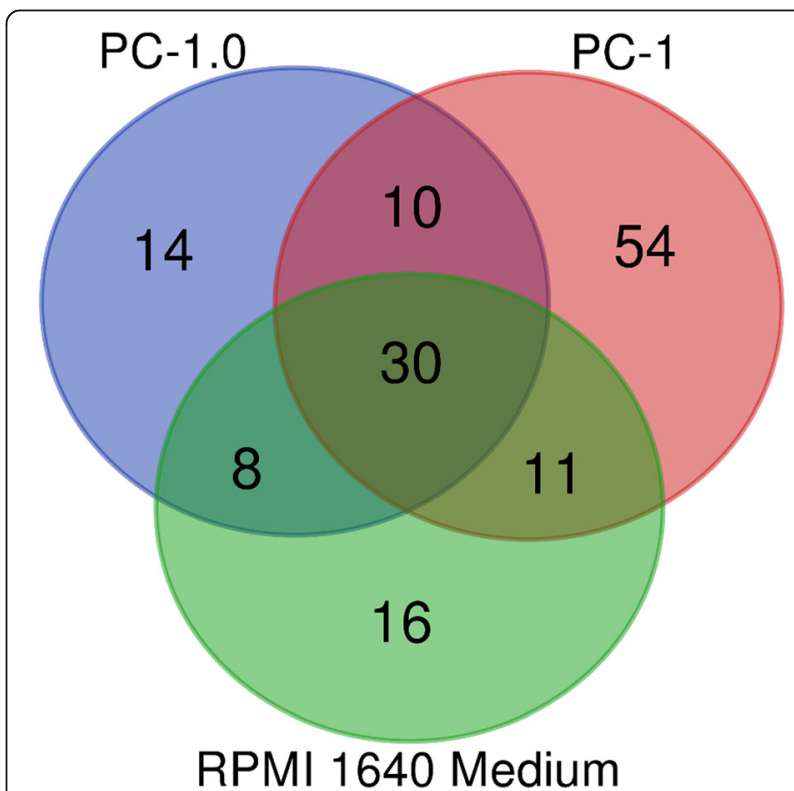

Fig. 4 The results of MS in the serum-containing group were shown by a Venn diagram. As a result, 14 protein only exists in the supernatant of PC-1.0 cell lines. Among them, 6 protein, which contain values, may be as candidate DFs 
Table 2 DAVID Cluster Analysis

\begin{tabular}{lll}
\hline Enrichment Score: 1.9097618864692167 & \\
\hline Category & Term & P-Value \\
\hline UP_KEYWORDS & Secreted & $3.83 E-04$ \\
UP_SEQ_FEATURE & disulfide bond & 0.001971 \\
UP_SEQ_FEATURE & signal peptide & 0.003347 \\
UP_KEYWORDS & Disulfide bond & 0.003354 \\
GOTERM_CC_DIRECT & GO:0005615 extracellular space & 0.003597 \\
GOTERM_CC_DIRECT & GO:0005576 extracellular region & 0.006005 \\
UP_KEYWORDS & Signal & 0.006989 \\
\hline
\end{tabular}

modification was methionine oxidation. The maximum number of missing cleavage sites was 2 , and the FDR was controlled at less than $1 \%$.

\section{Bioinformatic analysis}

Because special structural characteristics of secreted proteins usually include a signal peptide, SignalP4.1 software was used to search the current hamster protein database and to construct the hamster secreted protein database (http://www.cbs.dtu.dk/services/SignalP/, probability >0.90) [10]. In the serum-containing medium group, RPMI 1640 medium was used as the negative control to eliminate the error caused by unlabeled samples. The results were screened from the database of hamster secretory proteins. Subsequently, the DAVID (http://david.abcc.ncifcrf.gov/) [11] and STING (https:// string-db.org/) [12] bioinformatics software tools were used to analyze protein functions and possible interacting proteins. Finally, Survival analysis of patients with the different DFs was analyzed with Kaplan Meier Plotter (http://kmplot.com/analysis/index.php?p=service\&cancer=pancancer_rnaseq) [13]. The Gene Expression Profiling Interactive Analysis (GEPIA) database was used to analyze the expression of the target genes in the TCGA database (http://gepia.cancer-pku.cn/) [14]. The expression level of YWHAG in different cancer stages was analyzed with the online analysis platform UALCAN (http://ualcan.path.uab.edu/index.html) [15].

\section{YWHAG uptake assay}

Western blotting was performed as described previously [9]. Primary antibodies against YWHAG and $\beta$-actin (Abcam, USA) were used. Samples with equivalent amounts of total protein $(20 \mu \mathrm{g})$ were loaded. Western blot signals were quantified using an Amersham Imager 600 (GE Healthcare, Little Chalfont, UK), and band signals were expressed as relative protein amounts compared to

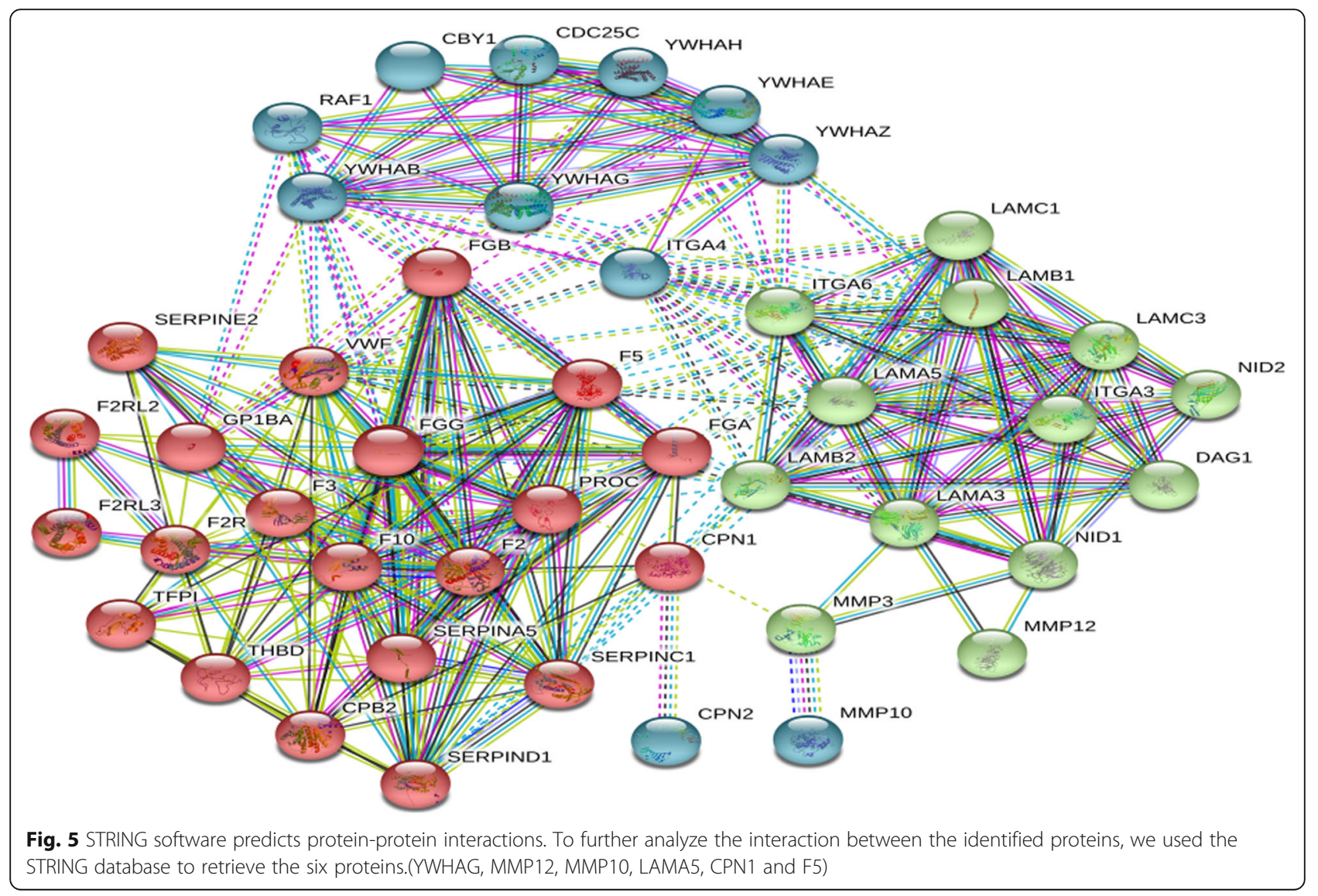




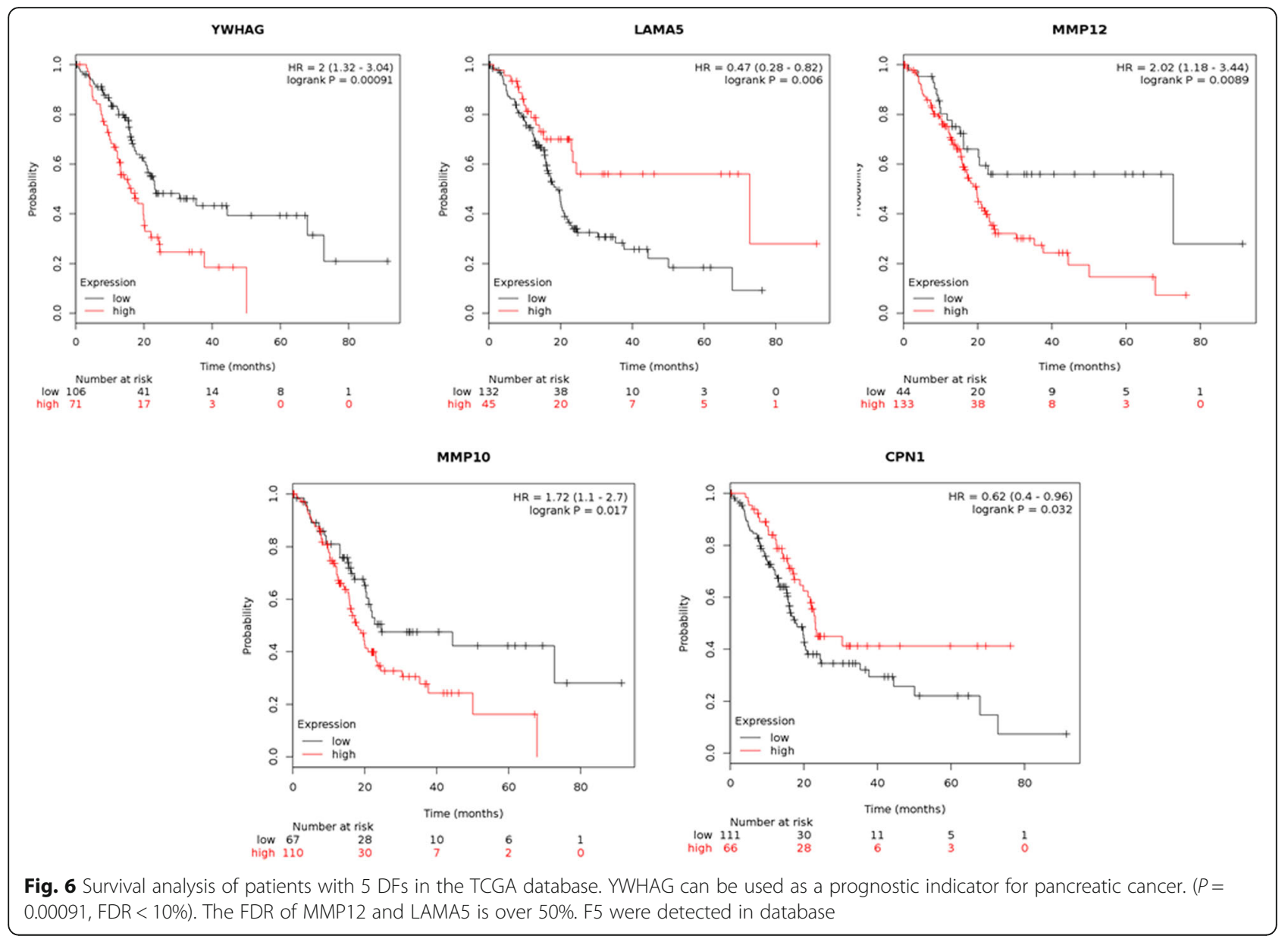

$\beta$-actin. The purified supernatant from PC-1.0 cells were added to PC-1 cells at $60-70 \%$ confluence. The YWHAG protein level of the PC- 1 cells was tested by western blot analysis after another $24 \mathrm{~h}$ of culture. Human pancreatic cancer cell lines AsPC-1 and Capan-2, which have morphological and functional characteristics similar to PC-1.0 and PC- 1 cells, respectively, were used to determine if the results from hamster cells coincide with human pancreatic cancer cell lines.

\section{Statistical analysis}

Statistical analyses were conducted and graphics were generated using GraphPad Prism 6.0. $P<0.05$ was considered statistically significant in this study. Comparisons of quantitative data were made using Student's t-test.

\section{Results}

\section{Biological functional validation of serum-free culture conditions}

According to the purpose of this study, samples of highly invasive PC-1.0 cells were processed and divided into the serum-free and serum-containing groups (Fig. 1). In the serum-free group, PC-1.0 cells were treated with three different serum starvation methods, and the cell content of sample 1 was the lowest (Fig. 2). Subsequently, we extracted the corresponding supernatant to prepare conditioned medium and incubated $\mathrm{PC}-1$ cells with this medium. It was found that a large number of PC-1 cells died after incubation with conditioned medium from Sample 1; the number of PC-1 cells after incubation with Sample 2 medium exhibited a relative decrease, and there was no obvious separation trend; and the growth status of PC-1 cells after treatment with Sample 3 medium changed (Fig.3). Therefore, the serum-free treatment process changed the composition of the original supernatant, which may lead to errors in the final analysis results.

\section{Identification of DFs}

According to the biological function verification results, samples 2 and 3 were subjected to subsequent mass spectrometry verification (Additional file 1). From the serum-containing medium experimental group, samples 4, 5 and 6 were taken for follow-up experiments. Each group was separated by SEC and analyzed by mass spectrometry. The results were searched by Mascot software. The database species used were hamsters and cattle. The 


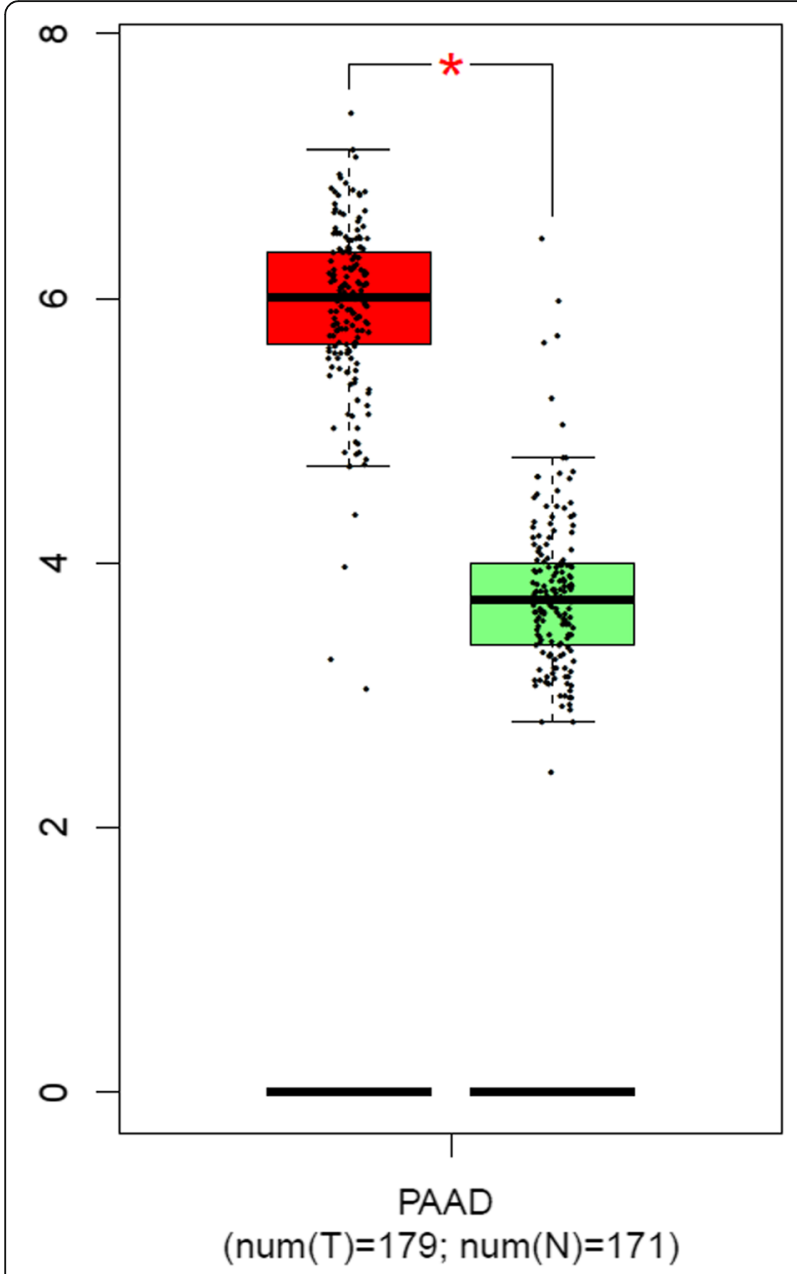

Fig. 7 Expression level of YWHAG in pancreatic cancer and normal tissue in the TCGA database results were then searched to generate the database of hamster secreted proteins (see Table 1, Additional files 2 and 3 ). The results showed that the number of secreted proteins in samples 4, 5 and 6 was small, which indicated that the serum had a great influence on the number of final identified proteins, but the results were more authentic and more conducive to further verification than those from the serum-free groups. The data from the serum-containing experimental groups were integrated and analyzed. Only 6 secretory proteins were expressed in PC-1.0cells: matrix metalloelastase 12 (MMP12), matrix metalloproteinase 1 (stromelysin-2, MMP10), laminin subunit alpha-5 (LAMA5), Tyr-3/Trp5 monooxygenase activator protein gamma (14-3-3 eta, YWHAG), carboxypeptidase $\mathrm{N}$ catalytic chain (CPN1) and coagulation factor V (THPH2) (Fig. 4).

\section{Identification of YWHAG as a prognostic biomarker of pancreatic cancer}

Through online functional annotation cluster analysis with DAVID software, the secretory signal cluster was found (enrichment score: 1.91, Table 2). To further analyze the interaction between the identified proteins, we used the STRING database to retrieve the above six proteins (Fig. 5). We used online software to perform clinical correlation analysis of these six proteins. The results showed that YWHAG could be used as a prognostic biomarker for pancreatic cancer (Fig. 6). We used the Cancer Genome Atlas (TCGA) data visualization web tool GEPIA to analyze the expression of YWHAG in normal and cancer tissues. The results showed higher expression levels of YWHAG in pancreatic cancer than

\section{Expression of YWHAG in PAAD based on individual cancer stages}

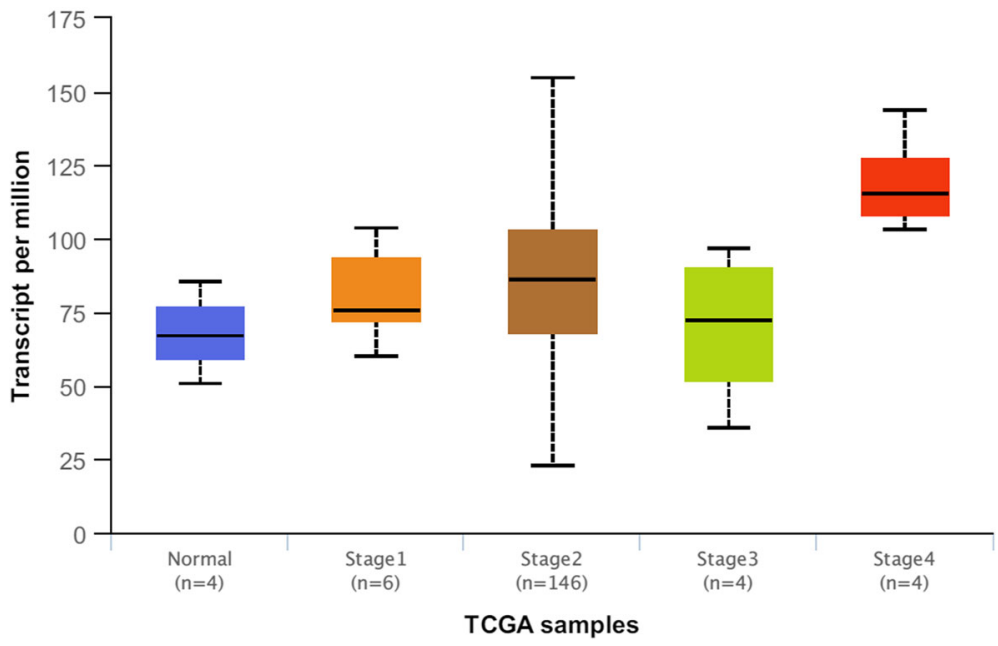

Fig. 8 Expression level of YWHAG in different individual pancreatic cancer stages in the TCGA database 

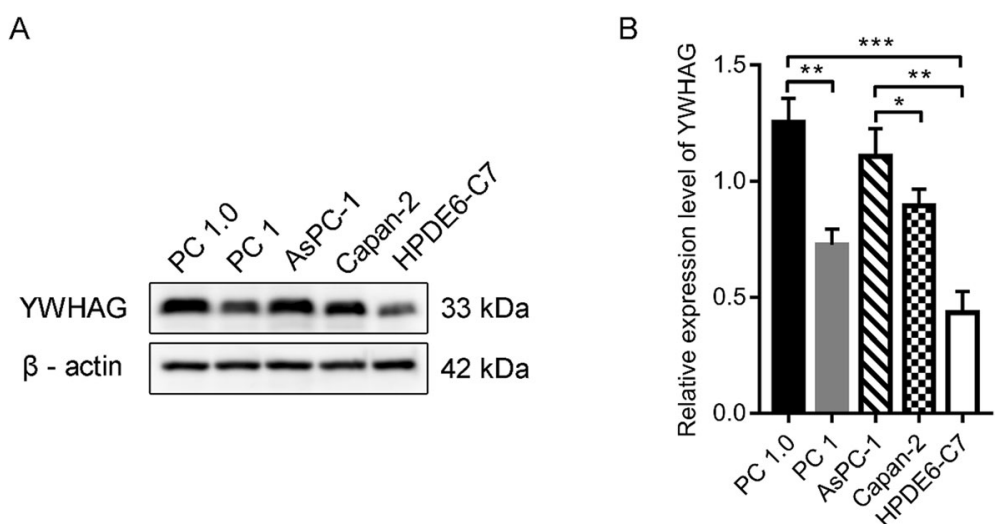

Fig. 9 YWHAG protein levels were detected using western blot analysis. a, Western blot validation of YWHAG from cells lines. b, Quantitative analysis of YWHAG is shown. ${ }^{*} P<0.05,{ }^{* *} P<0.01,{ }^{* * *} P<0.001$

in normal tissue in the TCGA cohort $(P<0.01)$ (Fig. 7). Validation of the YWHAG expression level in different cancer stages from TCGA data showed higher expression levels of YWHAG in the advanced stage than in the early stage (Fig. 8). The Western blot results showed that YWHAG was highly expressed in the highly invasive PC-1.0 cell line (Fig. 9). The expression level of YWHAG in $\mathrm{PC}-1$ cells increased with the increase of cocultured PC-1.0-derived DF (Fig. 10).

\section{Discussion}

With the development of mass spectrometry technology, a large number of secreted proteins have been identified. These newly discovered proteins have been shown to be tumor markers [16]. When tumor cells secrete proteins into the extracellular environment, some of these proteins can change the tumor microenvironment and promote tumor growth [17]. In our previous work, we found that the supernatant of highly invasive PC-1.0 cells contained DFs. DFs can induce morphologic changes in and increase the invasive ability of low-invasive PC- 1 cells. DFs play an

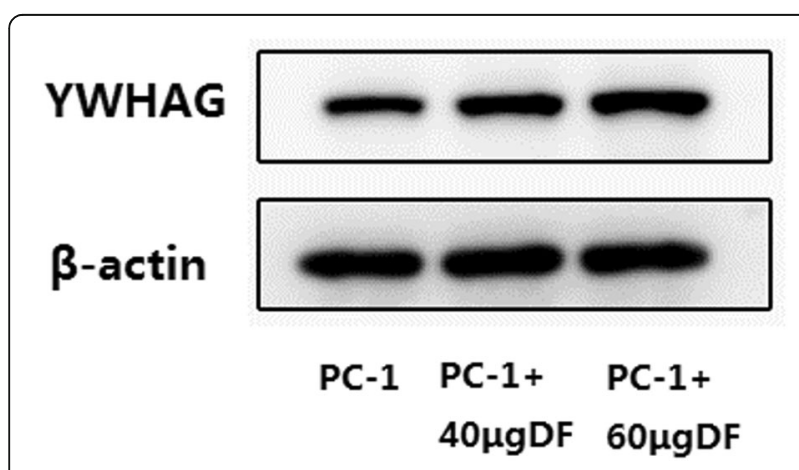

Fig. 10 The expression level of YWHAG in PC-1 cells increased with the increase of cocultured PC-1.0-derived DF. ${ }^{* *} P<0.01$ important role in understanding the molecular mechanism of invasion and metastasis of cancer cells. In this study, we identified DFs using a mass spectrometry-based proteomic approach.

In this study, two different pretreatment methods were used to isolate samples by combined size exclusion chromatography (SEC) and to preliminarily analyze the secreted proteomes of pancreatic cancer cell lines. The results showed 1496 identified proteins in the serum-free medium group and 230 in the serum-contained medium group. In the serum-free experimental group, we found that the short-term serum starvation process can lead to changes in the secretory status. Therefore, the secretory status in serum-containing culture medium is more similar to the real secretory status and is thus more meaningful for later clinical verification and application. In the serumcontaining medium group, we used SEC to isolate and enrich the secreted proteins in the supernatant. Although there was no quantitative data, the secreted proteins were also qualitatively identified through data mining and analysis. Six proteins were identified, namely, MMP12, MMP10, LAMA5, YWHAG, CPN1 and THPH2. Among these six proteins, MMP12 and MMP10 are members of the matrix metalloproteinase family, and have been proven to be closely related to pancreatic cancer [18, 19]. LAMA5 is an important component of the extracellular matrix, which can regulate cell adhesion and promote cancer cell metastasis [20]. CPN1 can prevent the accumulation of polypeptides and regulate the secretory hormone level [21]. Baine MJ et al. reported that the level of coagulation factor $\mathrm{V}$ was found to be significantly different in an analysis of peripheral monocytes from pancreatic cancer patients and might be related to tumor stage [22]. YWHAG is a member of a highly conserved family of proteins that participates in many intracellular signal transduction processes and plays an important role in cell survival and proliferation [23-26]. However, the role of YWHAG in pancreatic 
cancer progression is still unclear. In our previous intracellular proteomic study, YWHAG was also the key gene in the PPI network [9]. The expression of YWHAG was found to be closely related to pancreatic cancer stage via TCGA database analysis. Furthermore, survival analysis suggested that patients with higher expression levels of YWHAG showed a worse overall survival rate than those with lower YWHAG expression.

\section{Conclusion}

Given the above findings, several alternative proteins were identified as pancreatic cancer dissociation factors via a pair of homologous pancreatic cancer cell lines with different metastatic abilities. These results provided us with more comprehensive information on pancreatic cancer invasion and metastasis. YWHAG is suggested as a potential prognostic biomarker and a sensitive therapeutic target for pancreatic cancer invasion and metastasis.

\section{Supplementary information}

Supplementary information accompanies this paper at https://doi.org/10. 1186/s12885-020-6522-3.

Additional file 1. Results of Mass Spectrometry in the serum-free group. Additional file 2. Results of mass spectrometry in the serum-containing group.

Additional file 3. Hamster secreted protein Database.

\section{Acknowledgements}

Not applicable.

\section{Authors' contributions}

$\mathrm{PL}$ analyzed the data and writed the paper. PL and HJ performed mass spectrometry analysis assay and analyzed the data. LK performed western blot assay. YW and $\mathrm{KL}$ are responsible for culturing cells. XT and BS designed the experiment and revised the paper. All authors read and approved the final manuscript.

\section{Funding}

The present study were funded by the National Natural Science Foundation of China (Grant Number: 81902953) Liaoning Provincial Natural Science Foundation Project (Grant Number: 180530068), the Outstanding Young Doctor Fund of China Medical University (Grant Number: QGZD2018050), and 345 Talent Project of Shengjing Hosiptal of China Medical University. The grants had no role in the design of the study, collection, analysis, and interpretation of data, and writing of the manuscript.

\section{Availability of data and materials}

All data generated or analyzed during this study are included in this published article and its supplementary information files.

\section{Ethics approval and consent to participate}

Not applicable.

\section{Consent for publication}

Not applicable.

\section{Competing interests}

The authors declare that they have no competing interests.

\section{Author details}

'Department of General Surgery, Shengjing Hospital of China Medical University, Shenyang 110004, China. ${ }^{2}$ Cardiff Institute of Tissue Engineering and Repair, School of Dentistry, Cardiff University, Cardiff CF14 4XY, UK.

Received: 13 August 2019 Accepted: 7 January 2020

Published online: 20 January 2020

\section{References}

1. Siegel RL, Miller KD, Jemal A. Cancer statistics, 2019. CA Cancer J Clin. 2019; 69(1):7-34.

2. Zheng RS, Sun KX, Zhang SW, et al. Report of cancer epidemiology in China, 2015. Zhonghua Zhong Liu Za Zhi. 2019;41(1):19-28.

3. Ansari D, Tingstedt B, Andersson B, et al. Pancreatic cancer: yesterday, today and tomorrow. Future Oncol. 2016:12:1929-46.

4. Ryan DP, Hong TS, Bardeesy N. Pancreatic adenocarcinoma. N Engl J Med. 2014:371(22):2140-1.

5. Vasen $\mathrm{H}$, Ibrahim I, Ponce CG, et al. Benefit of surveillance for pancreatic cancer in high-risk individuals: outcome of long-term prospective follow-up studies from three European expert centers. J Clin Oncol. 2016;34:2010-9.

6. Ansari D, Torén W, Zhou Q, et al. Proteomic and genomic profiling of pancreatic cancer. Cell Biol Toxicol. 2019;35(4):333-43.

7. Tan X, Tamori $Y$, Egami H, et al. Analysis of invasion-metastasis mechanism in pancreatic cancer: involvement of tight junction transmembrane protein occludin and MEK/ERK signal transduction pathway in cancer cell dissociation. Oncol Rep. 2004;11(5):993-8.

8. Zhou L, Tan X, Wang W, et al. Analysis of invasion-metastasis in pancreatic cancer: correlation between the expression and arrangement of tight junction protein-2 and cell dissociation in pancreatic cancer cells. Mol Med Rep. 2010;3(1):149-53.

9. Liu X, Weng Y, Liu P, et al. Identification of PGAM1 as a putative therapeutic target for pancreatic ductal adenocarcinoma metastasis using quantitative proteomics. Onco Targets Ther. 2018;11:3345-57.

10. Petersen TN, Brunak S, von Heijne G, Nielsen H. SignalP 4.0: discriminating signal peptides from transmembrane regions. Nat Methods. 2011;8:785-6.

11. Huang da W, Sherman BT, Lempicki RA. Systematic and integrative analysis of large gene lists using DAVID bioinformatics resources. Nat Protoc. 2009; 4(1):44-57.

12. Szklarczyk D, Morris JH, Cook H, et al. The STRING database in 2017: qualitycontrolled protein-protein association networks, made broadly accessible. Nucleic Acids Res. 2017:45(D1):D362-D8.

13. Nagy A, Lanczky A, Menyhart O, Gyorffy B. Validation of miRNA prognostic power in hepatocellular carcinoma using expression data of independent datasets. Sci Rep. 2018:8:9227.

14. Tang Z, Li C, Kang B, et al. GEPIA: a web server for cancer and normal gene expression profiling and interactive analyses. Nucleic Acids Res. 2017;45(W1): W98-W102

15. Chandrashekar DS, Bashel B, Balasubramanya SAH, et al. UALCAN: a portal for facilitating tumor subgroup gene expression and survival analyses. Neoplasia. 2017:19:649-58.

16. Ansari D, Aronsson L, Sasor A, et al. The role of quantitative mass spectrometry in the discovery of pancreatic cancer biomarkers for translational science. J Transl Med. 2014;12:87

17. Klemm F, Joyce JA. Microenvironmental regulation of therapeutic response in cancer. Trends Cell Biol. 2015;25(4):198-213.

18. Zhang JJ, Zhu Y, Xie KL, et al. Yin Yang-1 suppresses invasion and metastasis of pancreatic ductal adenocarcinoma by downregulating MMP10 in a MUC4/ ErbB2/p38/MEF2Cdependent mechanism. Mol Cancer. 2014;13(1):130.

19. Balaz $\mathrm{P}$, Friess $\mathrm{H}$, Kondo $\mathrm{Y}$, et al. Human macrophage metalloelastase worsens the prognosis of pancreatic cancer. Ann Surg. 2002;235(4):519-27.

20. Bair EL, Chen ML, McDaniel K, et al. Membrane type 1 matrix metalloprotease cleaves laminin-10 and promotes prostate cancer cell migration. Neoplasia. 2005;7:380-9.

21. Skidgel RA, Erdös EG. Structure and function of human plasma carboxypeptidase $\mathrm{N}$, the anaphylatoxin inactivator. Int Immunopharmacol. 2007:7(14):1888-99.

22. Baine MJ, Menning M, Smith LM, et al. Differential gene expression analysis of peripheral blood mononuclear cells reveals novel test for early detection of pancreatic cancer. Cancer Biomark. 2012;11(1):1-14.

23. Raungrut $\mathrm{P}$, Wongkotsila A, Champoochana N, et al. Knockdown of 14-33gamma suppresses epithelial-Mesenchymal transition and reduces 
metastatic potential of human non-small cell lung Cancer cells. Anticancer Res. 2018;38(6):3507-14.

24. Jiang $W$, Luo H, Shen Z, et al. Down-regulation and gene hypermethylation of the 14-3-3 gamma in uterine leiomyoma. Front Biosci (Landmark edition). 2016;21:1286-95.

25. Lee YS, Lee JK, Bae Y, et al. Suppression of 14-3-3gamma-mediated surface expression of ANO1 inhibits cancer progression of glioblastoma cells. Sci Rep. 2016;6:26413.

26. Yoo JO, Kwak SY, An HJ, et al. miR-181b-3p promotes epithelialmesenchymal transition in breast cancer cells through Snail stabilization by directly targeting YWHAG. Biochim Biophys Acta. 2016;1863(7 Pt A):1601-11.

\section{Publisher's Note}

Springer Nature remains neutral with regard to jurisdictional claims in published maps and institutional affiliations.

Ready to submit your research? Choose BMC and benefit from:

- fast, convenient online submission

- thorough peer review by experienced researchers in your field

- rapid publication on acceptance

- support for research data, including large and complex data types

- gold Open Access which fosters wider collaboration and increased citations

- maximum visibility for your research: over $100 \mathrm{M}$ website views per year

At BMC, research is always in progress.

Learn more biomedcentral.com/submissions 